\title{
Rapamycin has no effect on fibrosis-associated gene expression or extracellular matrix accumulation when administered to animals with established or early allograft vasculopathy
}

Gavin J. Murphy, FRCS

Michael L. Nicholson, MD, FRCS

From the University Department of Surgery, Leicester General Hospital, Leicester, United Kingdom.

Presented in part to the European Society of Organ Transplantation, Lisbon, Portugal, October 2001

Received for publication Nov 5, 2002; revisions requested Jan 21, 2003; revisions received Jan 22, 2003; accepted for publication March 11, 2003.

Address for reprints: Mr Gavin J. Murphy, Specialist Registrar, Department of Cardiac Surgery, Bristol Royal Infirmary, Marlborough St, Bristol, United Kingdom BS2 8HW (E-mail: gavinmurphy@ hotmail. com).

J Thorac Cardiovasc Surg 2003;126: 2058-64

Copyright $\odot 2003$ by The American Association for Thoracic Surgery

$0022-5223 / 2003 \$ 30.00+0$

doi:10.1016/j.jtcvs.2003.03.004
Background: Most patients with functioning heart transplants have established and progressive chronic allograft vasculopathy, a fibroproliferative process for which there is no effective treatment. Coronary artery disease is characterized by histologic evidence of extracellular matrix accumulation (fibrosis). This study compares the effect of rapamycin administered to rats with established allograft vasculopathy on histologic indices of disease progression, extracellular matrix accumulation (fibrosis), and the expression of genes known to regulate extracellular matrix turnover in this model.

Methods: Lewis recipients of Fisher 344 rat thoracic to abdominal aorta transplants were administered rapamycin starting at 8,12 , and 16 weeks posttransplant or no treatment. Six grafts in each group were harvested at 24 weeks. Vascular remodeling and collagen accumulation (Sirius red) were measured by computerized histomorphometry of aortic sections. mRNA was extracted from frozen tissue, and the expression of fibrosis-associated genes was studied by means of semiquantitative reverse transcriptase-polymerase chain reaction.

Results: Rapamycin had no effect on the progression of early or established allograft vasculopathy with regard to intimal thickening, remodeling, extracellular matrix accumulation, or profibrotic gene expression, regardless of the time commenced.

Conclusion: The attenuation of the fibroproliferative response in rodents by rapamycin is not seen if the onset of rapamycin therapy is delayed.

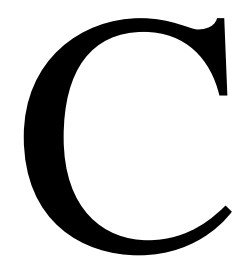

hronic allograft dysfunction (CAD) occurs as a consequence of a fibroproliferative response to tissue injury. It is defined histologically by allograft vasculopathy and organ fibrosis ${ }^{1}$ and results ultimately in organ dysfunction and failure. The majority of patients with functioning transplants have established and progressive $\mathrm{CAD},{ }^{2,3}$ with allograft vasculopathy detectable using intracoronary ultrasound in up to $75 \%$ of heart transplant recipients at 1 year. ${ }^{4}$ No therapy to date has been shown to halt the progression of this process. Rapamycin, a macrolide antibiotic derived from the actinomycete Streptomyces hygroscopicus, has been shown to attenuate the fibroproliferative response to injury in rats after mechanical injury and ischemia-reperfusion injury, as well as in animal models of CAD in vivo. ${ }^{5,6}$ This study assesses whether rapamycin administered to rats after the development of allograft vasculopathy had an effect on histologic indices of disease progression, extracellular matrix (ECM) accumulation (fibrosis), or the expression of genes known to regulate ECM turnover in this model. 

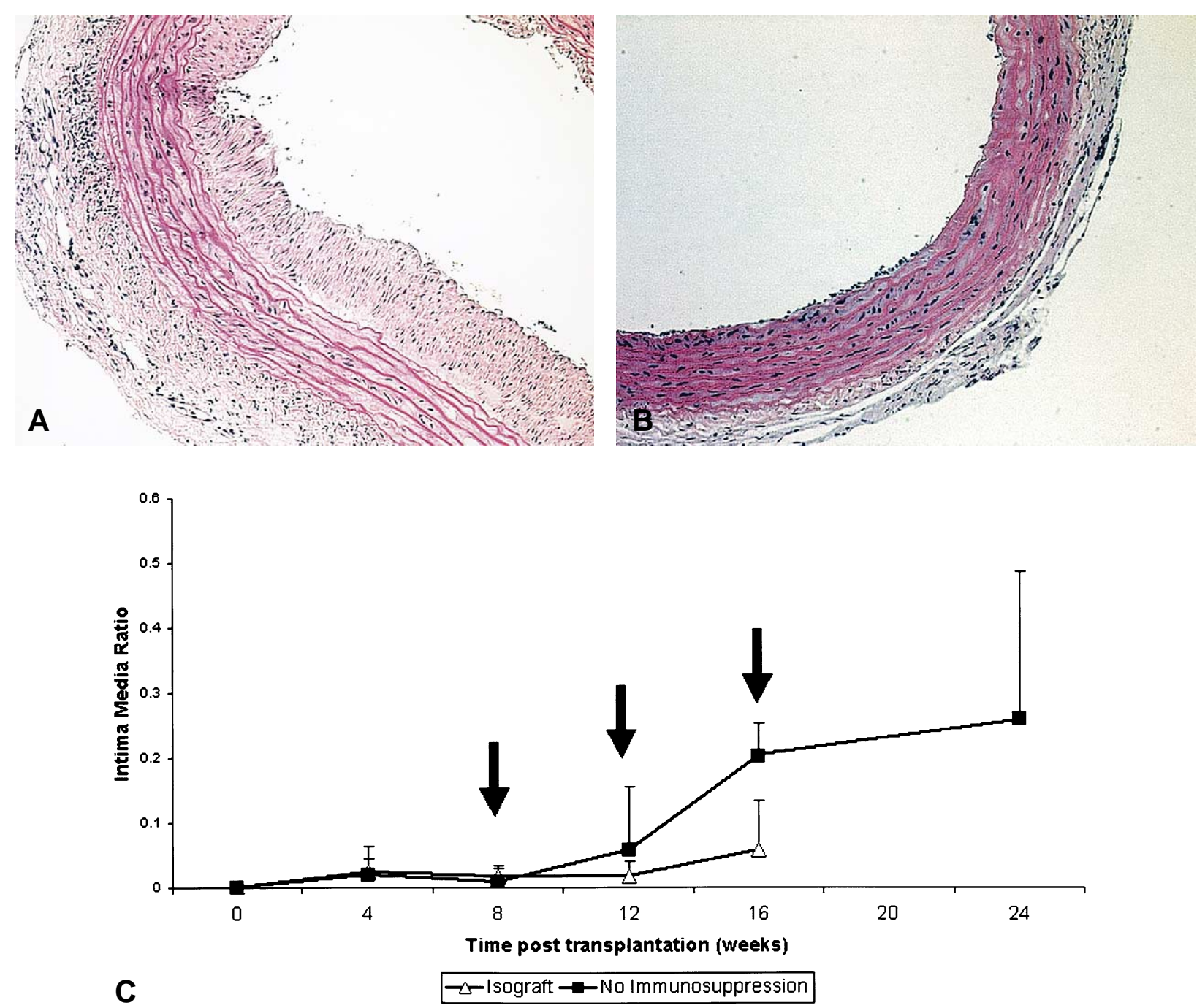

Figure 1. Representative photomicrographs of hematoxylin-eosin-stained section of donor rat aorta (A) and aortic allografts (B) at 24 weeks. Untreated allografts have a dense transmural inflammatory infiltrate associated with intimal and medial thickening, as well as striking neoadventitia formation. These changes were not attenuated by rapamycin started at 8, 12, or 16 weeks. Stages of neointimal development at which rapamycin was commenced (C).

\section{Experimental Design and Methodology \\ Experimental Model}

The thoracic aorta to abdominal aorta allograft model as described by Mennander and colleagues ${ }^{7}$ was used. A segment of the descending thoracic aorta approximately $3 \mathrm{~cm}$ in length was excised, thoroughly perfused with phosphate-buffered saline, and used as a transplant. Fisher (F)344 and Lewis (LEW) rats were used as donors and recipients, respectively. Ischemic injury to the graft was minimized by immersion in an ice bath at $4^{\circ} \mathrm{C}$ between procedures. Through a midline laparotomy incision, the segment of thoracic aorta was anastomosed end to end as an interposition graft to the recipient abdominal aorta using 9-0 Prolene suture. The graft was transplanted into a heterotopic position below the renal arteries and above the bifurcation forming a loop in the recipient abdomen.

Animals were kept in a controlled environment with unlimited access to feed and water. Graft harvest was performed in heavily anesthetized rats, after which the animal was allowed to die by exsanguination.

\section{Drugs}

Rapamycin (Sirolimus; Wyeth-Ayerst, Princeton, NJ) was prepared twice weekly as a working solution of $5 \mathrm{mg} / \mathrm{mL}$ in distilled water. Solutions were stored at $4^{\circ} \mathrm{C}$ and protected from ultraviolet light exposure. Drugs were administered orally by gavage.

\section{Experimental Groups}

All experiments were performed on F344 to LEW allografts, which received cyclosporine (Neoral; Novartis, East Hanover, NJ) $5 \mathrm{mg} \cdot \mathrm{kg} \cdot$ day for the first 14 days only to attenuate early acute rejection and induce tolerance. This was followed by a period without immunosuppression. They were then started on rapamycin $0.5 \mathrm{mg} \cdot \mathrm{kg} \cdot$ day at the following times posttransplantation: group 1 , 


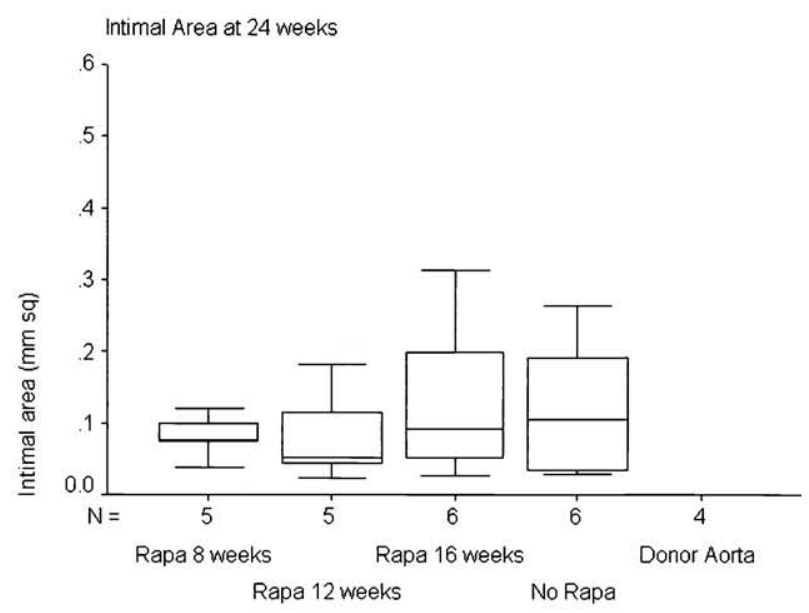

A Group

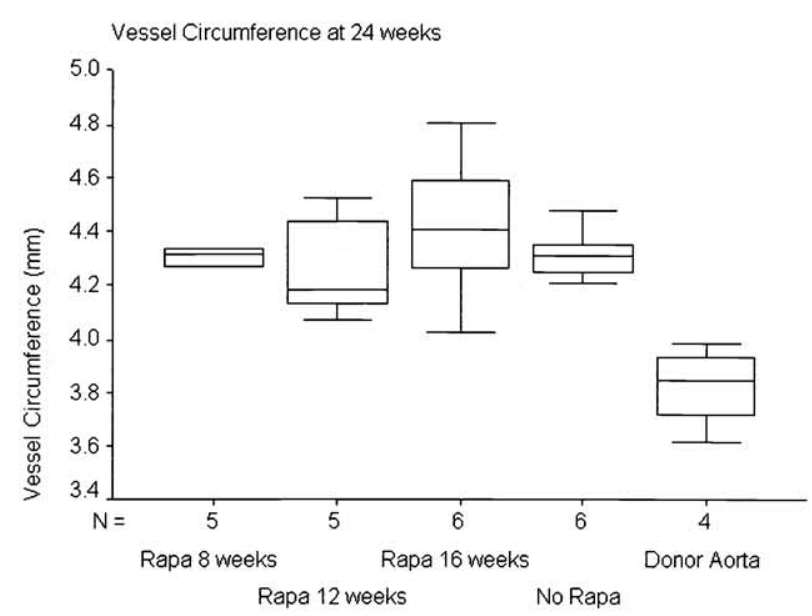

B Group

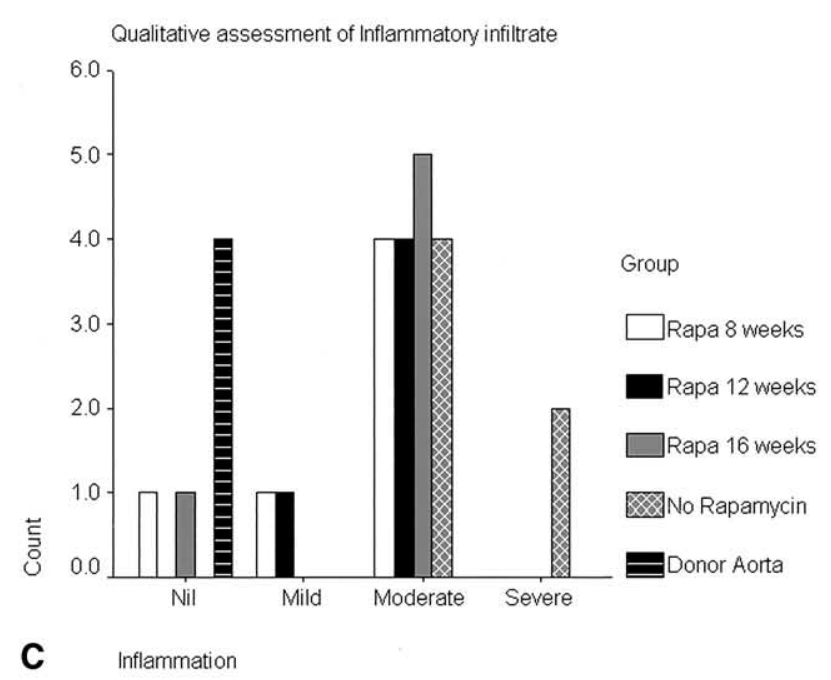

Figure 2. A-C, Results of histologic analysis. Rapamycin has no effect on the development of the neointima or expansive remodeling whether introduced at 8,12 , or 16 weeks (Kruskall Wallis $P>.05$ for intimal/medial ratio and vessel circumference). Median \pm SD (boxes); $95 \%$ Cl (whiskers). There was no significant reduction in the severity of the inflammatory infiltrate between the rapamycin-treated groups (Pearson's $\chi^{2}$ with Yates' correction $\boldsymbol{P}>.05$ ).

8 weeks; group 2, 12 weeks; group 3, 16 weeks; and group 4, no rapamycin.

These time points correspond to macrophage and lymphocyte infiltration and expansive remodeling ( 8 weeks), early neointimal development and expansive remodeling (12 weeks), and neointimal thickening and almost complete and expansive remodeling (16 weeks) (Figure 1). Six rats in each group were killed at 24 weeks. Rapamycin at $0.5 \mathrm{mg} \cdot \mathrm{kg} \cdot$ day has been shown to completely inhibit the development of allograft vasculopathy in this model when administered from the time of transplantation. ${ }^{8}$

\section{Allograft Gene Expression Using Reverse}

\section{Transcriptase-Polymerase Chain Reaction}

Total mRNA was extracted from aortic tissue, and complementary DNA molecules were synthesized by reverse transcriptase (RT).
These cDNA species were amplified by polymerase chain reaction (PCR) and quantified in an enzyme-linked immunosorbent assay system. Relative quantitation was performed by comparison of the signal intensity to that of the housekeeping gene $\beta$-actin. These techniques have been described in more detail elsewhere. ${ }^{9}$ The probe and primer sequences used in these experiments have also been published. ${ }^{10}$

\section{Histologic Analysis}

Segments of the aortic graft were embedded in paraffin wax, and multiple sections were stained with hematoxylin-eosin. The level of inflammatory infiltrate was assessed semiquantitatively and categorized as follows: none (no inflammatory cells visualized), mild (endothelialitis, inflammatory cell localized to the endothelium), moderate (dense inflammatory cell infiltrate in the inner- 
most layer of the vessel wall), or severe (dense inflammatory cell infiltrate throughout all layers of the vessel wall).

The vessel circumference and area fraction of the intima and media were quantified using a computer image analysis system. The intima was defined as the area between the endothelium and the internal elastic lamina, and the media was defined as the area between the internal and external elastic laminas. Paraffin-embedded sections were also stained with Sirius red, and the level of ECM staining was quantified using computerized histomorphometry as described previously. ${ }^{11}$

\section{Substances Assessed}

To take into account all the factors that influence smooth muscle cell proliferation, migration, and deposition of ECM during neointima formation, the following species were studied with RTPCR: matrix metalloproteinase (MMP)2, MMP9, transforming growth factor (TGF)- $\beta$, tissue inhibitor of metalloproteinase 1 , and collagen III.

\section{Analysis of Results \\ The levels of gene expression and histomorphometric measure- ments of intimal thickening expressed as the intimal media ratio, vascular remodeling expressed as vessel circumference (of the internal elastic lamina), and collagen accumulation expressed as a product of the percentage mean media Sirius red staining and the medial area were compared using nonparametric statistical analy- sis. Comparisons of the level of inflammatory infiltrate were per- formed using Pearson's chi-square test. Statistical analysis was performed using the Statistical Package for the Social Sciences Version 8.0 (SPSS Inc, Chicago, Ill).}

\section{Results}

\section{Results of Histologic Analysis}

Allografts undergo progressive expansive remodeling process that is associated with neointima and marked neoadventitia formation (Figure 1 and Figure 2, $A, B$ ). There was no difference between any of the treatment groups in terms of intimal area, vessel circumference (Figure 2, $A, B$ ), or the severity of the inflammatory infiltrate (Figure 2, $C$ ). There was also no difference between the allograft groups in terms of relative medial ECM content (Kruskall Wallis $P>.05$ ) (Figure 3).

\section{Results of RT-PCR}

There were no significant differences between the groups for any of the genes studied (Figure 4), although it is noteworthy that all allograft groups had elevated TGF- $\beta$, MMP2, and MMP9 levels relative to the donor aorta.

\section{Discussion}

Rapamycin had no effect on the progression of vasculopathy in rat aortic allografts when administered to grafts with early cellular changes but no neointima or to grafts with developing or established intimal hyperplasia. The beneficial effect of rapamycin on CAD development in this rodent model was therefore lost after 8 weeks. There was also no

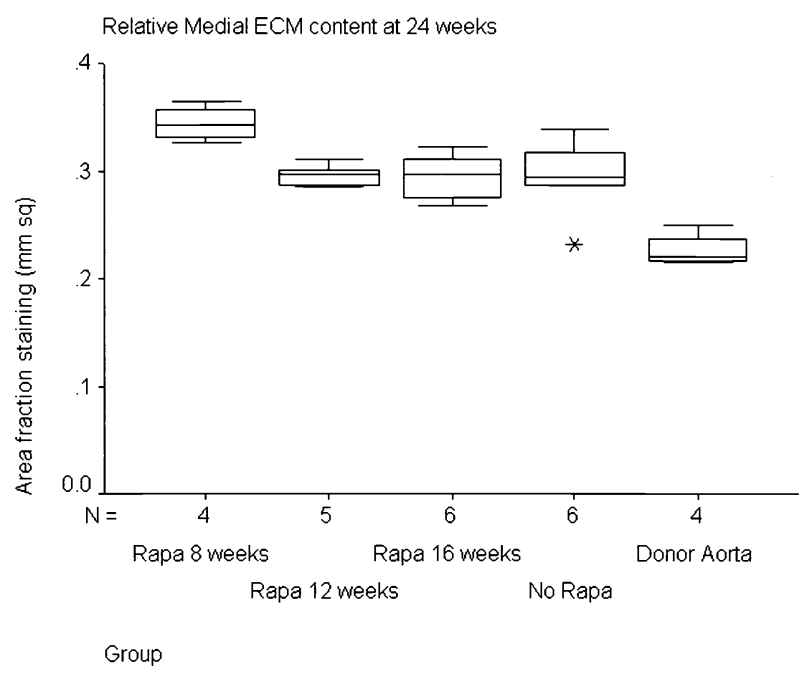

Figure 3. Relative medial ECM content at 24 weeks. There was no difference between the groups in medial collagen content and adventitial collagen density (Kruskall Wallis $\boldsymbol{P}>$.05). Median \pm SD (boxes); 95\% Cl (whiskers). ECM, Extracellular matrix.

difference between any of the rapamycin-treated allograft groups in the expression of genes that regulate the fibroproliferative response.

The rapamycin dose used was smaller than in other studies in which rapamycin was shown to inhibit established (3 $\mathrm{mg} \cdot \mathrm{kg} \cdot$ day intraperitoneally [IP]) or de novo CAD $\left(0.5-6 \mathrm{mg} \cdot \mathrm{kg} \cdot\right.$ day IP) in rat allografts. ${ }^{5,12-15}$ Rapamycin at the $0.5 \mathrm{mg} \cdot \mathrm{kg} \cdot$ day oral dose equates to a serum trough level of approximately $1 \mathrm{ng} / \mathrm{mL}$ in LEW rats. ${ }^{16}$ This dose has been shown in previous studies to significantly prolong rat renal and cardiac allograft survival in the high-responder Brown Norway (BN) to LEW model ${ }^{16}$ and to significantly inhibit the allograft inflammatory infiltrate, intimal hyperplasia, and vessel remodeling in the F344 to LEW model. ${ }^{8}$ However, these serum levels do not correlate with suggested therapeutic range levels in humans $(5-15 \mathrm{ng} / \mathrm{mL})^{17}$. Higher oral doses of rapamycin are poorly tolerated by rats, with significant weight loss reported at doses greater than $0.8 \mathrm{mg}$ - $\mathrm{kg} \cdot$ day. ${ }^{16}$ It is possible that the rats may have increased their clearance of the drug over time, and that this study may have benefited from serum rapamycin levels on the day of cull. There was no significant inhibition of MMP9 (a correlate of the severity of the inflammatory infiltrate in this model $)^{18}$ in rapamycin-treated versus untreated allografts, however, semiquantitative assessment of the inflammatory infiltrate indicated attenuation of the inflammatory response to the treated allografts. This suggests that increased clearance of rapamycin has not occurred. Other criticisms relate to the use of a high-responder model in the analysis of factors affecting the development of $\mathrm{CAD},{ }^{12}$ because the intense cellular immune response tends to obscure the contribution of other important etiologic mechanisms. 

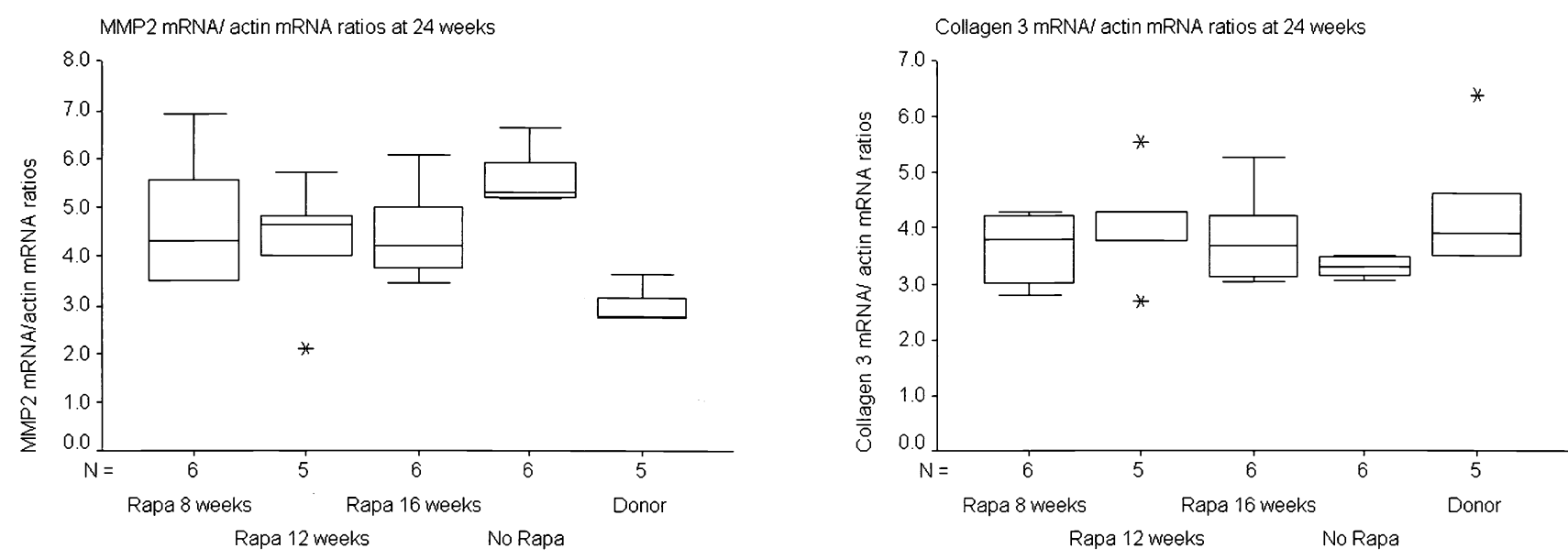

A Group

D Group
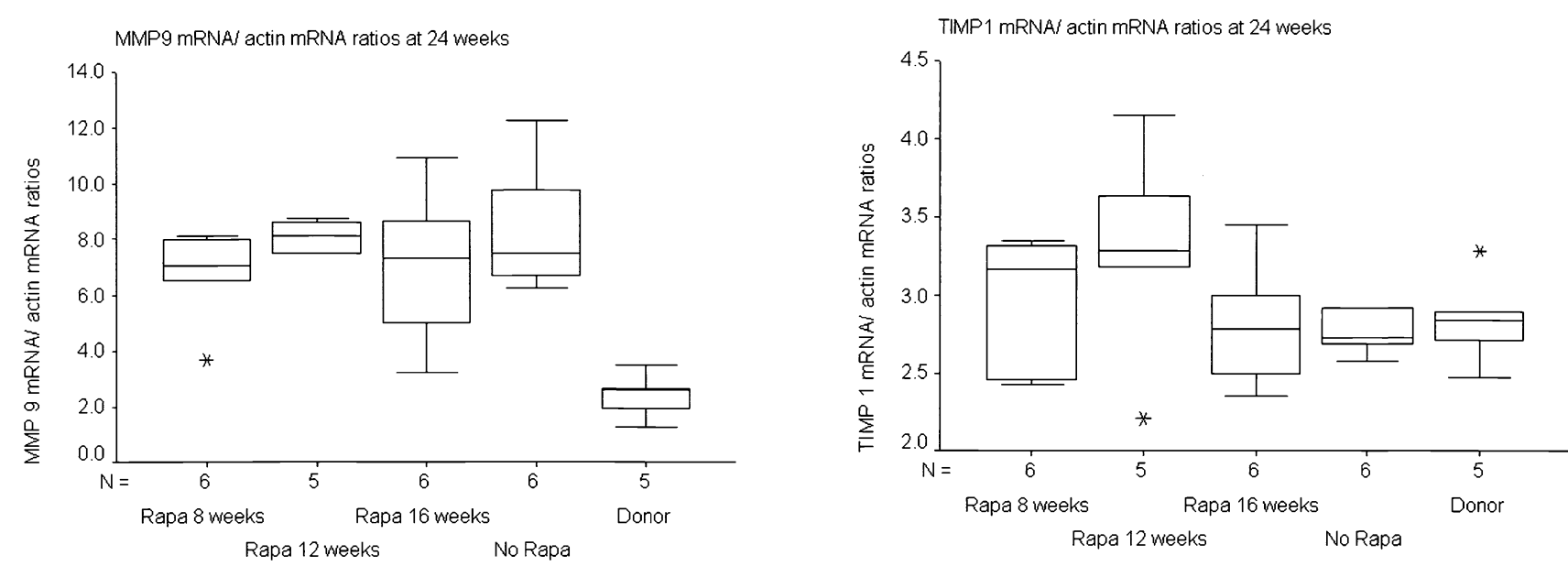

B Group

E Group

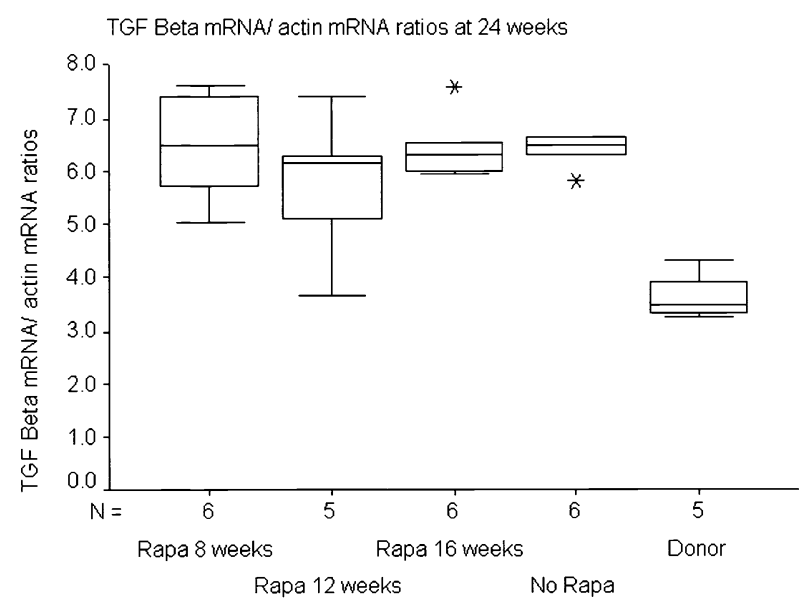

C Group

Figure 4. A-E, Gene expression in allografts at 24 weeks (see text). Median \pm SD (boxes); $95 \%$ Cl (whiskers); outliers $\left(^{*}\right)$. MMP, Matrix metalloproteinase; TGF, transforming growth factor; TIMP, tissue inhibitor of metalloproteinase. 
In 1991, Meiser and colleagues ${ }^{13}$ reported that rapamycin at $1.5 \mathrm{mg} \cdot \mathrm{kg} \cdot$ day inhibited CAD in de novo heterotopic rat cardiac allografts in a high-responder BN to LEW model. BN and LEW rats are mismatched at major human leukocyte antigen loci (RT- $1^{\mathrm{n}}$ versus RT- ${ }^{1}$ ), and the development of CAD in this model occurs in association with an intense cell-mediated response with intimal thickening occurring predominantly between 30 and 40 days. Morris and colleagues ${ }^{5}$ reported similar findings with femoral artery allografts in the same high-responder combination. In this latter study, the importance of inhibiting the early cellular response was underscored by the diminished efficacy of rapamycin if administration was delayed. Delaying onset of rapamycin treatment by 14,21 , or 30 days inhibited the progression of CAD only at large doses $(3 \mathrm{mg} \cdot \mathrm{kg}$ - day IP at 14 and 21 days and $6 \mathrm{mg} \cdot \mathrm{kg} \cdot$ day IP at 30 days) and was of marginal statistical significance only at this later time point ( $28 \%$ vs $49 \%, P=.03) .{ }^{5}$ This study did not, however, consider the effect of rapamycin once intimal hyperplasia had become established as in the current study. Poston and colleagues ${ }^{12}$ subsequently demonstrated reversal of established allograft vasculopathy in the low-responder Piebaldvirol-glaxo to August Copenhagen Irish rat cardiac allograft model, which develops significant intimal thickening between 30 and 90 days posttransplantation. Rapamycin ( $3 \mathrm{mg}$ $\cdot \mathrm{kg} \cdot$ day IP) significantly reversed intimal thickening when administered between 60 and 90 days. ${ }^{12}$ Significant weight loss was noted in these animals; therefore it is questionable whether the observed effect was because of a direct effect of rapamycin on the fibroproliferative response or simply a result of drug toxicity.

There are few studies that have demonstrated any regression of CAD once it is established. In the weakly immunogenic Wistar Furth to LEW model, retransplantation to the donor strain up to 40 days reversed the inflammatory infiltrate and prevented the development of CAD. ${ }^{19}$ In highresponder models, however, retransplantation was seen to reduce but not prevent the development of CAD. Moreover, in these stronger models retransplantation after a critical period reversed the associated cellular infiltrate, whereas the intimal proliferation not only did not diminish but continued to worsen. ${ }^{20-22}$

F344 to LEW rat renal allografts retransplanted to the F344 strain showed reversal of the process up to a certain time interval (12 weeks) after which structural changes, particularly fibrosis, not only did not diminish but continued to worsen. ${ }^{23}$ In the same rat strain combination, retransplantation of cardiac allografts to the donor strain was seen to reduce levels of mononuclear infiltration but not levels of myointimal proliferation. ${ }^{14}$ These findings indicate that progressive organ injury (ie, the fibroproliferative response) beyond a certain point may become autonomous and alloantigen independent. Of equal importance is the indication that the initial insults, whether alloantigen dependent or independent, occurring at an early stage posttransplant are crucial in the later development of CAD. This study demonstrates that in F344 to LEW allografts, rapamycin does not seem to affect the fibroproliferative response after 8 weeks. This may be attributable to inadequate immunosuppression in a high-responder model (as indicated by persistently elevated MMP9 mRNA levels in allografts); however, it may also be attributable to a failure of rapamycin to inhibit later stages of the fibroproliferative response. This latter suggestion is supported by the elevated MMP2 and TGF levels in allografts at 24 weeks. In a randomized clinical trial in renal transplant recipients with biopsyproven $\mathrm{CAD},{ }^{24}$ cyclosporine dose reduction and the administration of rapamycin did not prevent the progressive decline in renal function. These findings present clinical and experimental evidence that rapamycin does not attenuate the fibroproliferative response in allografts once it is established.

\section{References}

1. Kouwenhoven EA, IJzermans JN, de Bruin RW. Etiology and pathophysiology of chronic transplant dysfunction [Review.]. Transpl Int. 2000;13:385-401.

2. Hosenpud JD, Novick RJ, Breen TJ, Keck B, Daily P. The Registry of the International Society for Heart and Lung Transplantation: twelfth official report-1995. J Heart Lung Transplant. 1995;14:805-15.

3. Cecka JM, Terasaki PI. The UNOS Scientific Renal Transplant Registry. United Network for Organ Sharing. Clin Transpl. 1994;1-18.

4. Yeung AC, Davis SF, Hauptman PJ, Kobashigawa JA, Miller LW, Valantine HA, et al. Incidence and progression of transplant coronary artery disease over 1 year: results of a multicenter trial with use of intravascular ultrasound. Multicenter Intravascular Ultrasound Transplant Study Group. J Heart Lung Transplant. 1995;14:S215-20.

5. Morris RE, Cao W, Huang X, Gregory CR, Billingham ME, Rowan R, et al. Rapamycin (Sirolimus) inhibits vascular smooth muscle DNA synthesis in vitro and suppresses narrowing in arterial allografts and in balloon-injured carotid arteries: evidence that rapamycin antagonizes growth factor action on immune and nonimmune cells. Transplant Proc. 1995;27:430-1.

6. Jain S, Bicknell GR, Whiting PH, Nicholson ML. Rapamycin reduces expression of fibrosis-associated genes in an experimental model of renal ischaemia reperfusion injury. Transplant Proc. 2001;33:556-8.

7. Mennander A, Tiisala S, Halttunen J, Yilmaz S, Paavonen T, Hayry P. Chronic rejection in rat aortic allografts. An experimental model for transplant arteriosclerosis. Arterioscler Thromb. 1991;11:671-80.

8. Murphy GJ, Bicknell GR, Nicholson ML. Rapamycin inhibits vascular remodeling in an experimental model of allograft vasculopathy and attenuates associated changes in fibrosis-associated gene expression. J Heart Lung Transplant. 2003;22:533-41.

9. Bicknell GR, Shaw JA, Pringle JH, Furness PN. Amplification of specific mRNA from a single human renal glomerulus, with an approach to the separation of epithelial cell mRNA. J Pathol. 1996;180: 188-93.

10. Jain S, Bicknell GR, Nicholson ML. Molecular changes in extracellular matrix turnover after renal ischaemia-reperfusion injury. $\mathrm{Br} J$ Surg. 2000;87:1188-92.

11. Moreso F, Gratin C, Vitria J, Condom E, Poveda R, Cruzado JM, et al. Automatic evaluation of renal interstitial volume fraction. Transplant Proc. 1995;27:2231-2.

12. Poston RS, Billingham M, Hoyt EG, Pollard J, Shorthouse R, Morris $\mathrm{RE}$, et al. Rapamycin reverses chronic graft vascular disease in a novel cardiac allograft model. Circulation. 1999;100:67-74. 
13. Meiser BM, Billingham ME, Morris RE. Effects of cyclosporin, FK506, and rapamycin on graft-vessel disease [See comments.]. Lancet. 1991;338:1297-8.

14. Schmid C, Heemann U, Azuma H, Tilney NL. Rapamycin inhibits transplant vasculopathy in long-surviving rat heart allografts. Transplantation. 1995;60:729-33.

15. Gregory CR, Huie P, Billingham ME, Morris RE. Rapamycin inhibits arterial intimal thickening caused by both alloimmune and mechanical injury. Its effect on cellular, growth factor, and cytokine response in injured vessels. Transplantation. 1993;55:1409-18.

16. DiJoseph JF, Fluhler E, Armstrong J, Sharr M, Sehgal SN. Therapeutic blood levels of sirolimus (rapamycin) in the allografted rat. Transplantation. 1996;62:1109-12.

17. Saunders RN, Metcalfe MS, Nicholson ML. Rapamycin in transplantation: a review of the evidence [Review.]. Kidney Int. 2001;59:3-16.

18. Murphy GJ, Bicknell GR, Nicholson ML. Microemulsion cyclosporine inhibits vascular remodeling and attenuates associated changes in pro-fibrotic gene expression in an experimental model of allograft vasculopathy. Br J Surg. 2002;89:1055-61.

19. Forbes RD, Zheng SX, Gomersall M, Guttmann RD. Irreversible chronic vascular rejection occurs only after development of advanced allograft vasculopathy: a comparative study of a rat cardiac allograft model using a retransplantation protocol. Transplantation. 1997;63: 743-9.

20. Schmid C, Heemann U, Tilney NL. Retransplantation reverses mononuclear infiltration but not myointimal proliferation in a rat model of chronic cardiac allograft rejection. Transplantation. 1996; 61:1695-9.

21. Hullett DA, Geraghty JG, Stoltenberg RL, Sollinger HW. The impact of acute rejection on the development of intimal hyperplasia associated with chronic rejection. Transplantation. 1996;62:1842-6.

22. Mennander A, Hayry P. Reversibility of allograft arteriosclerosis after retransplantation to donor strain. Transplantation. 1996;62:526-9.

23. Tullius SG, Heemann U, Hancock WW, Azuma H, Tilney NL. Longterm kidney isografts develop functional and morphologic changes that mimic those of chronic allograft rejection. Ann Surg. 1994;220:42535.

24. Saunders RN, Metcalfe MS, Murphy GJ, Bicknell GR, White SA, Nicholson ML. Rapamycin does not improve renal function or reduce profibrotic gene expression in chronic allograft nephropathy [Abstract.]. Br J Surg. 2001;88(Suppl 1):26. 